\title{
The use of optical and infrared techniques for the restoration of the frescoes damaged by earthquake: a case study - the fresco of Giacomo Farelli in the Church of Santa Maria della Croce di Roio (L’Aquila, Italy)
}

S. Sfarra ${ }^{1}$, C. Ibarra-Castanedo ${ }^{2}$, D. Ambrosini ${ }^{1}$, D. Paoletti ${ }^{1}$, A. Bendada ${ }^{2} \&$ X. Maldague ${ }^{2}$

${ }^{I}$ Department of Mechanical, Management \& Energy Engineering, University of L'Aquila, Monteluco di Roio, Italy

${ }^{2}$ Department of Electrical and Computer Engineering, Laval University, Quebec City, Canada

\begin{abstract}
The 2009 L'Aquila earthquake occurred in the region of Abruzzo, in central Italy. The main shock was rated 6.3 on the moment magnitude scale; its epicentre was near L'Aquila, the capital of Abruzzo. Earthquakes mark the history of L'Aquila, a city built on the bed of an ancient lake: the city was struck in $1315,1349,1452,1501,1646,1703$, and 1706 . Some of its most revered buildings were badly affected by the earthquake. Among them there is the Santa Maria della Croce di Roio Church, built in 1625, expanding a small chapel (1221) dedicated to St. Leonard. The cycle of frescoes by Giacomo Farelli at this Church expresses aspects of Marian devotion of its time. The object of our study is a Farelli's fresco that represents the discovery of the Statue of Our Lady. The non-destructive testing prior to the earthquake of 2009, made by ESPI technique before and after restoration, and the thermographic testing following the earthquake, clearly identified a weakness of the structure, where the old subsurface cracks and detachments are once again evident. The thermographic image processing allowed us to identify the buried architectural structure.
\end{abstract}

Keywords: ESPI, IRT, fresco, earthquake, restoration. 


\section{Introduction}

The life of wall paintings depends critically on the status of the wall, and in this context the most decisive aspects are structural stability, moisture, and acidity. There are many causes that may lead to a decrease in the load-bearing capacity of a wall. Regarding the structure, distinctions should be made between cracks due to poor foundations, to insufficiently strong structural members, or to some external factors such as war, fire, or excessive loads (e.g. earthquake). In a simplified way we may say that the major causes of structural instability are defective foundations, disturbed load transfers, and insufficient cohesion. In the first two instances, there will be cracks that, in the worst case, continue to widen resulting in the eventual collapse of the building; in the third case the structure will have numerous hairline cracks caused by slight differences in settling, thermal loads, or other factors (Arendt [1]).

The case of Giacomo Farelli fresco in the Santa Maria della Croce di Roio Church, is unique in its kind because it combines aspects of structural instability, mistaken for insufficient cohesion of the fresco layers during the restoration of the years 1993 and 1994, with an excessive mechanical load due to the earthquake of 2009, which reopened the previously healed cracks.

It is important to note the congruence between the thermographic results after the earthquake, with the ESPI results, prior to the restoration of 1994. The nondestructive testing conducted by ESPI subsequently to the restoration, confirms the good results obtained only in the immediacy of the intervention. The structural instability previously mentioned is probably due to a buried architectural structure centrally to the fresco, detected by square pulse thermography that confirms the change of the Church geometry, built initially with a smaller planimetry. Pulsed phase thermography and principal component thermography algorithms also allowed us to detect some new cracks due to the mechanical stress of earthquake and an internal structure behind the fresco.

\section{Santa Maria della Croce di Roio Church and the fresco of Giacomo Farelli}

The Sanctuary of Santa Maria della Croce, was built in 1625, expanding a small chapel dedicated to St. Leonard (1221). The interior of the new Church, in the Baroque style, remained unfinished for several years and the façade was completed only in 1673 .

The friendship between the city of L'Aquila with Naples allowed an extensive exchange of artists, that brought in L'Aquila influences from the Neapolitan school, including the Maestro Andrea Vaccaro (1598-1670), whose pupil was Giacomo Farelli active in L'Aquila since the second half of the seventeenth century (Antonucci [2], Murri [3], Paoletti and Schirripa Spagnolo [4]).

Farelli executed two frescoes on the sides of the main altar depicting the two highlights of the Virgin Statue presence in the place where previously, as already 
mentioned, there was a chapel. In 1667 Farelli painted the fresco object of our study (Figure 1).

It represents with a plasticity enveloping, the discovery of the Statue in a niche of the Three Saints Wood in Ruvo di Puglia.

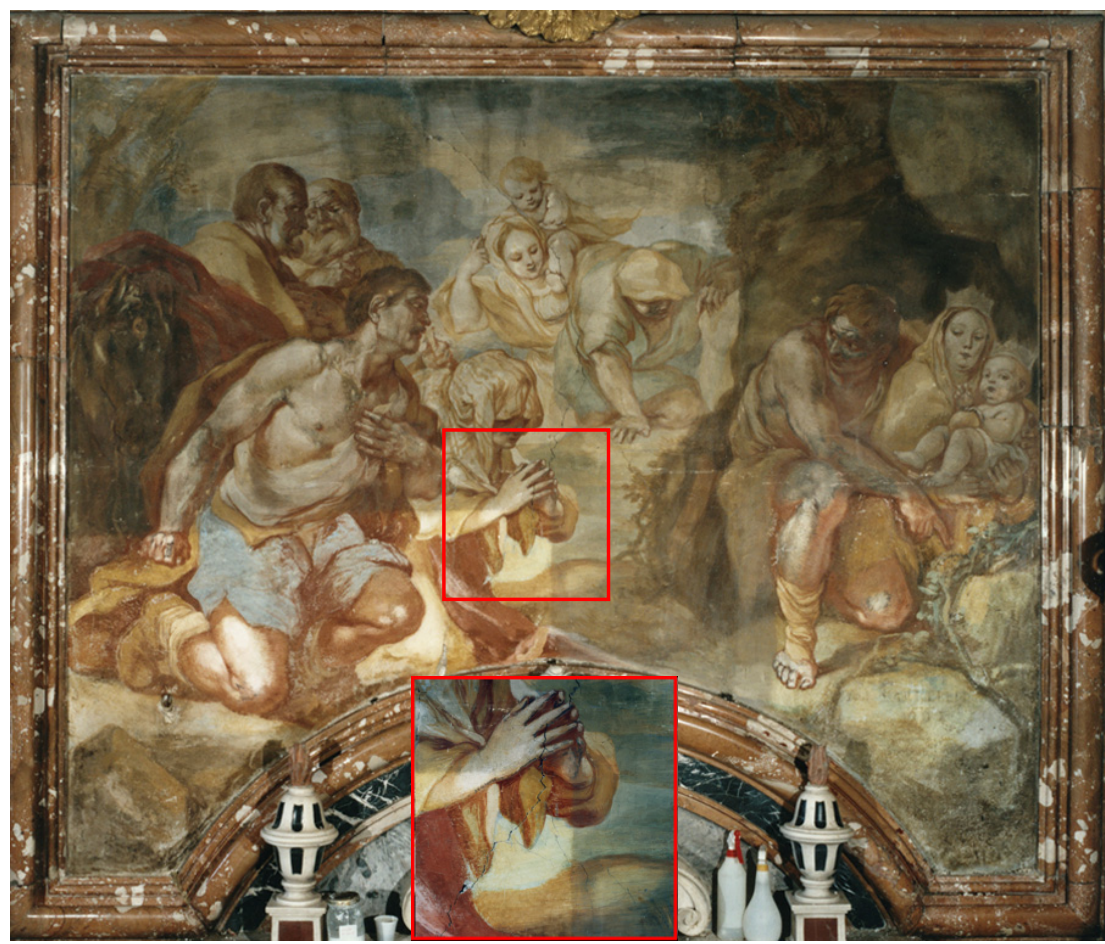

Figure 1: Fresco, "Discovery of the Statue" by G. Farelli (1667) before the restoration of 1994, and magnification of a particular area with cracks.

The fresco, which is approximately $5 \mathrm{~m}^{2}$ in size, was probably made using the technique typical of the time of the author, said of the true fresco. This method of mural painting must start applying the colours on the wet intonaco (painting plaster layer) as soon as it has been prepared and laid on the wall. The colours can thus be absorbed by the wet plaster. When it dries and hardens, the colours become one with plaster. Technically speaking the plaster does not "dry" but rather a chemical reaction occurs in which calcium carbonate is formed as a result of carbon dioxide from the air combining with the calcium hydrate in the wet plaster (Merrifield [5]).

The fresco has been tested with ESPI and thermographic methods. In the following we give some details on the techniques. 


\section{Electronic speckle pattern interferometry (ESPI)}

A diffusely scattering surface illuminated by laser light appears covered by a pattern of bright and dark spots, or speckles, distributed randomly in space. This occurs because neighbouring microscopic elements making up the surface produce random differences of the optical path for the scattered light. At any point, therefore, scattered waves arrive from many of these elements simultaneously and, as they are highly correlated, their instantaneous amplitudes add coherently. However, as the phases are random they may provide at any point constructive (bright speckle) as well as destructive (dark speckle) interference (Goodman [6]).

Considered by the majority of holographers as the stain of coherent illumination, this "annoyance" can still relay information about the surface characteristics as well as its displacement.

The combination of the imaged speckle pattern and a reference wavefront to produce a phase-referenced speckle pattern can be used in a way similar to holographic interferometry.

The idea of linking this speckle interferogram with a TV camera was the advantage that set these techniques apart from holography. The ability to capture images by a video system combined with enhancements achieved by subsequent electronic processing allowed the development of a new, more efficient method, called electronic speckle pattern interferometry, for using in situ.

The electronic speckle pattern interferometry (ESPI, also called TVholography) was developed as a method of producing interferometric data without using traditional holographic recording techniques (Butters and Leedertz [7], Macovski et al. [8], Schwomma [9]). Practically, ESPI can be viewed as the combination of holography and speckle interferometry (Ennos [10]), the holographic film being replaced by a CCD camera as the recording medium.

Obviously, the photosensor of the TV camera is not suitable for optical reconstruction of the hologram; therefore the reconstruction process is performed electronically and visualized on a monitor.

The signal picked up by the TV camera is converted into a corresponding video signal by the scanning action of a video camera. This video signal is electronically processed through an intermediate recording medium (commonly a frame grabber) before being displayed on a TV screen, so that the variations in the texture of the speckle are converted into a variation of brightness. This image is entirely equivalent to a holographic reconstructed image and possesses the same interferometric sensitivity.

In this way, the specklegrams are recorded under ambient parameter variations. Some irregularities of the corresponding correlation fringes allow us to detect the presence of detachments or cracks.

In this section we give only a brief practical description of the portable system used for the measurements; the full theory is well covered in the literature (Lokberg and Malmo [11], Paoletti and Schirripa Spagnolo [4]). Figure 2 shows, schematically, the experimental configuration for in situ diagnostics. Other configurations can be retrieved in literature (Paoletti and Schirripa 
Spagnolo [12], Kato et al. [13], Zanetta [14], Albrecht [15]). A laser diode $(\mathrm{P}=15 \mathrm{~mW})$ is used as the light source. The laser diode junction is temperature stabilized by a thermo-electric controller. Furthermore, the laser system includes a very low-noise current driver. The laser source is coupled to a polarization maintaining single mode fibre.

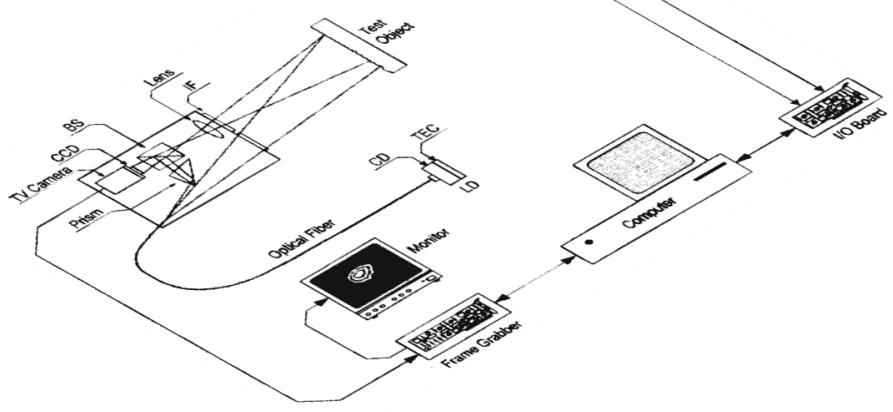

Figure 2: Experimental set up. BS: beam splitter cube; CD: current driver; $\mathrm{H}$ : humidity sensor; IF: interference filter; T: temperature sensor; TEC: thermo-electric controller.

The laser light emitter by the output end of the optical fibre directly illuminates the surface under investigation. A small part of the spherical wavefront, caught by a prism, serves as reference beam. A beam-splitter cube reflects the reference light onto the CCD sensor, where the object image is focused by an objective lens. An interference filter centred at the laser diode wavelength is introduced in front of the imaging lens to prevent external light from reaching the $\mathrm{CCD}$ camera. The images captured by the $\mathrm{CCD}$ camera are recorded by a PC-based frame-grabber. Besides, the PC system is equipped with temperature and relative humidity transducers. The short exposure time $(1 / 30 \mathrm{~s})$ of the ESPI technique provides a greater stability and tolerance of external disturbances with respect to traditional holographic techniques, therefore, the ESPI system can be used outside the research laboratory (Lokberg and Malmo [11]). To obtain a good quality ESPI interferogram, the system as well as the surrounding environment must remain stable, during the exposure time, to at least $\lambda / 8$.

A solution, which can mitigate these problems, consists of assembling all components in an optical head mounted on a high stiffness tripod (Thomson [16]). However, the effect of residual relative rigid displacement between the object and the optical head will be to reduce the fringe contrast, which can be partially recovered by image enhancement techniques, as shown in this work. 


\section{Square Pulse Thermography (SPT)}

Active thermography is a well-known NDT technique allowing fast inspection of large surfaces that has been extensively investigated (Maldague [17], Balageas et al. [18]). Data acquisition is fast and straightforward, as illustrated in Figure 3.

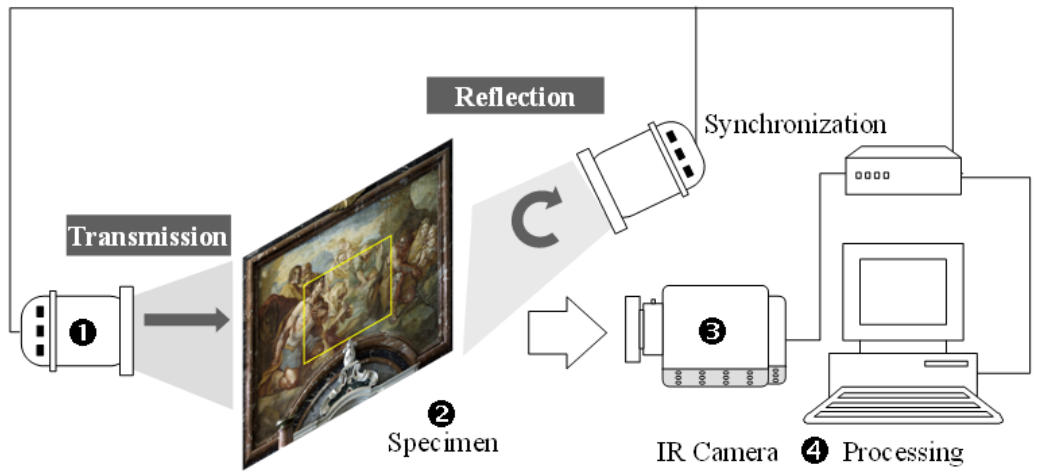

Figure 3: Experimental setup for square heating thermography.

In the square pulse configuration (Vavilov et al. [19], Arndt [20]) the specimen surface is submitted to a long square pulse (from a few seconds to several minutes), and the temperature raise and decay is register using an infrared camera and stored as a 3D matrix composed by $N$ thermograms, where $x$ and $y$ are the spatial coordinated, and $t$ is the time.

SPT data is generally processed to improve defect visibility and to performed quantitative characterization of defects. In this paper, we propose to use principal component thermography and pulsed phase thermography to process SPT data.

\subsection{Principal Component Thermography (PCT)}

Singular value decomposition (SVD) is an eigenvector-based transform that forms an orthonormal space, which is close to principal component analysis (PCA), with the difference that SVD simultaneously provides the PCAs in both row and column spaces. The SVD of an $M x N$ matrix $\mathbf{A}(M>N)$ can be calculated as follows (Rajic [21]):

$$
\mathrm{A}=\mathrm{URV}^{\mathrm{T}}
$$

where $\mathbf{U}$ is an $M x N$ orthogonal matrix, $\mathbf{R}$ being a diagonal $N x N$ matrix (with singular values of $\mathbf{A}$ present in the diagonal), $\mathbf{V}^{\mathbf{T}}$ is the transpose of an $N x N$ orthogonal matrix (characteristic time). Hence, in order to apply the SVD to thermographic data, the 3D thermogram matrix representing time and spatial variations has to be reorganised as a $2 \mathrm{D} M x N$ matrix A. This can be done by rearranging the thermograms for every time as columns in $\mathbf{A}$, in such a way that time variations will occur column-wise while spatial variations will occur rowwise. Under this configuration, the columns of $\mathbf{U}$ represent a set of orthogonal statistical modes known as empirical orthogonal functions (EOF) that describes spatial variations of data (Marinetti et al. [22]). The first EOF will represent the 
most characteristic variability of the data; the second EOF will contain the second most important variability, and so on. Usually, original data can be adequately represented with only a few EOFs. Typically, a 1000 thermogram sequence can be replaced by 10 or less EOFs.

\subsection{Pulsed Phase Thermography (PPT)}

Pulsed phase thermography (PPT) (Maldague and Marinetti [23], IbarraCastanedo and Maldague [24]) is another attracting technique, in which data is transformed from the time domain to the frequency domain using the onedimensional discrete Fourier transform (DFT):

$$
F_{n}=\Delta t \sum_{k=0}^{N-1} T(k \Delta t) \exp ^{(-j 2 \pi k k / N)}=\operatorname{Re}_{n}+j \operatorname{Im}_{n}
$$

where $j$ is the imaginary number $\left(j_{2}=-1\right), \mathrm{n}$ designates the frequency increment $(n=0,1, \ldots N), \Delta t$ is the sampling interval, and $\mathrm{Re}$ and $\mathrm{Im}$ are the real and the imaginary parts of the transform, respectively. In this case, real and imaginary parts of the complex transform are used to estimate the amplitude $A$, and the phase $\phi$ (Meola and Carlomagno [25]):

$$
A_{n}=\sqrt{\mathrm{Re}_{n}^{2}+\operatorname{Im}_{n}^{2}} \quad \text { and } \quad \phi_{n}=\tan ^{-1}\left(\frac{\operatorname{Im}_{n}}{\operatorname{Re}_{n}}\right)
$$

The DFT can be used with any waveform (e.g. transient pulsed thermographic profiles). Phase profiles for surface temperature are anti-symmetric, providing redundant information in both sides of the frequency spectra. In the following, only the positive part of the frequency spectra is used whilst the negative frequencies can be safely discarded. The phase is of particular interest in NDE given that it is less affected than raw thermal data by environmental reflections, emissivity variations, non-uniform heating, and surface geometry and orientation. These phase characteristics are very attractive not only for qualitative inspections but also for quantitative characterization of materials.

\section{Comparative results}

There are two steps in the examination of fresco damage: first the location and, second, the evaluation of the evolution of the defect with time. A simple visual inspection is the most straightforward method; the naked eye can be helped by magnification techniques. This method is widely used, economical and simple but can be time-consuming and may not give an identification of problems beneath the surface, defects can easily be over-looked. The ESPI method overcomes many of these shortcomings. With this technique the fresco under restoration has been studied. The fresco was interlaced by micro-cracks, evidence of forces at work in the wall. Without removing the fresco from its normal exhibition environment, the whole surface was analyzed; only some meaningful results are reported here. The map of some detachments between priming layers and the support is presented in Figure 4. 
With current methods of inspection, some detachments were not easily detected by the unaided eye. A particular area of the wall, which contained regions separated by cracks, was selected (Figs. 4 and 5). The same cracks, shown in Figure 1, were reproduced by the earthquake of 2009 (Figure 5).

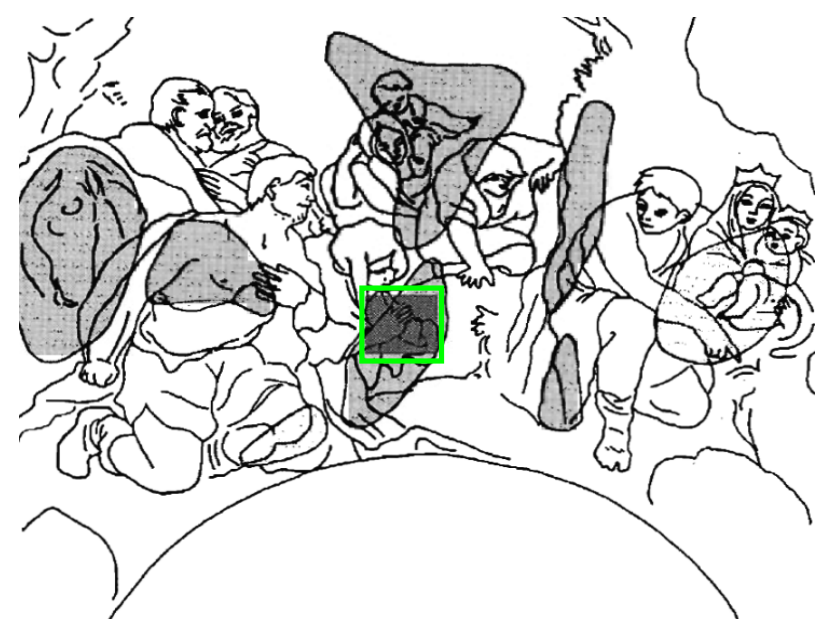

Figure 4: Drawing of the fresco "Discovery of the Statue", with highlighted zones of detachment, and the area studied by the integrated approach.

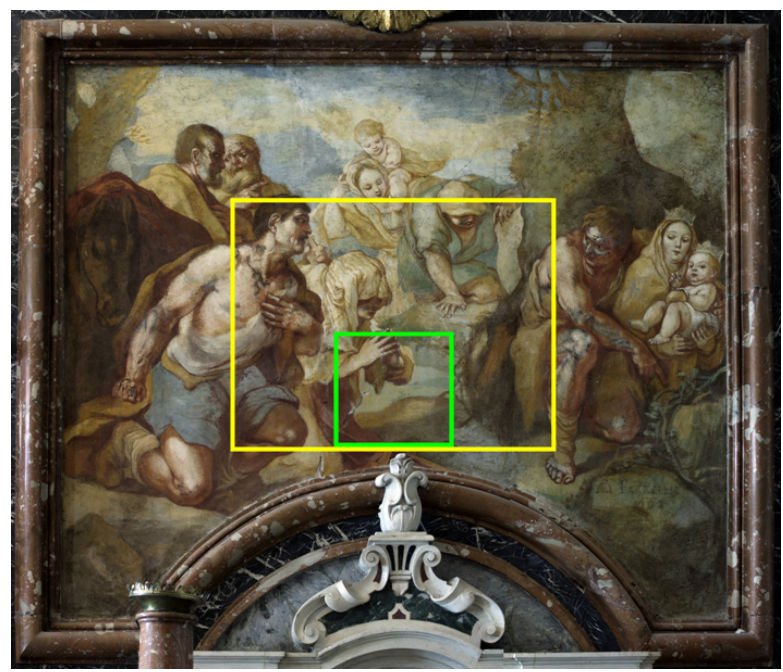

Figure 5: Fresco, "Discovery of the Statue" by G. Farelli (1667) after the earthquake of 2009 and with the areas studied by ESPI (green rectangle) and by IR thermography (yellow rectangle). (See online for colour version.) 
Figure 5, highlights both the zone studied by ESPI (green rectangle) and the area evaluated by thermography (yellow rectangle), which incorporates the previous area. The area covered with the green rectangle, measures $20 \mathrm{~cm}^{2}$ and was subjected to a brief thermal irradiation using a $150 \mathrm{~W}$ infrared lamp at a distance of approximately $1 \mathrm{~m}$.

Specklegrams were recorded continuously during the cooling process. Figure 6 shows a deformation map of the selected region, without any processing; the same fringe pattern filtered, enhanced, in false colour and with the indications of the final design, is shown in Figure 7.

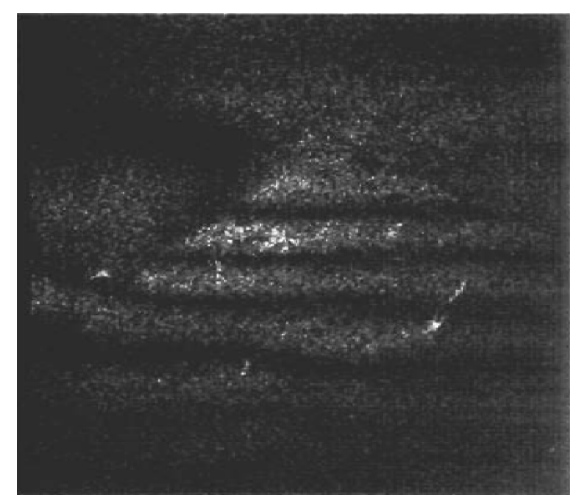

Figure 6: Specklecorrelogram without processing showing a crack (courtesy of the authors [4]).

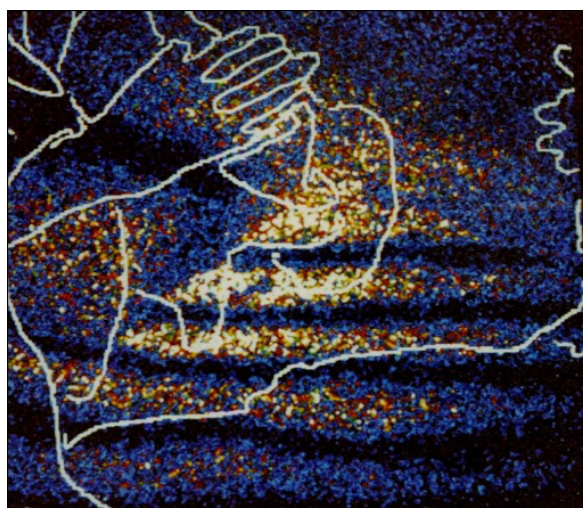

Figure 7: The same specklegram as in Figure 6 after processing and in false colour with the indication of the final design. (See online for colour version.)

Abrupt deviations along the trend of some correlation fringes are evident. These discontinuities correspond to the presence of cracks. A three-dimensional 
representation of the cracking area was obtained using the method proposed by Kreis (Figure 8) (Kreis [26]).

After a restoration it is important to monitor the state of the work of art with time in order to take further decisions. Until now, the examination has been primarily a matter of experience; the use of the portable ESPI system described above permits to make decisions about the conservation of the fresco during each phase of the restoration, taking into account factors such as the microclimate.

For this purpose some tests were made at the same location after the fresco has been restored. The restoration work is shown to be quite successful. Figure 9, which corresponds to the area reported in Figure 5 (green rectangle) shows how the cracks and the surrounding area have been repaired. Figure 10 shows some results obtained by infrared thermography after the earthquake.

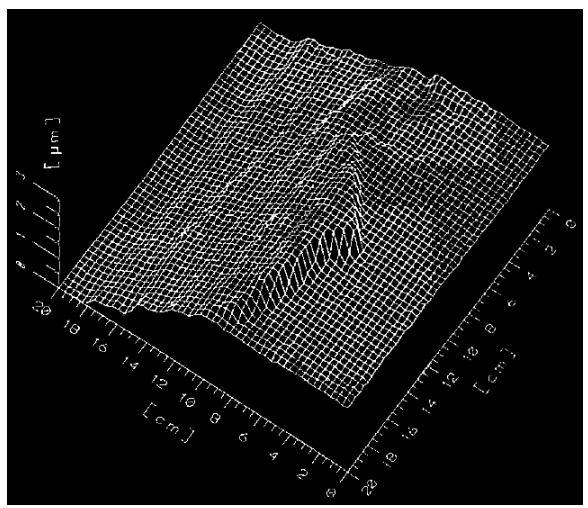

Figure 8: Three-dimensional representation of the deformation in the cracking area shown in Figure 6 (courtesy of the authors [4]).

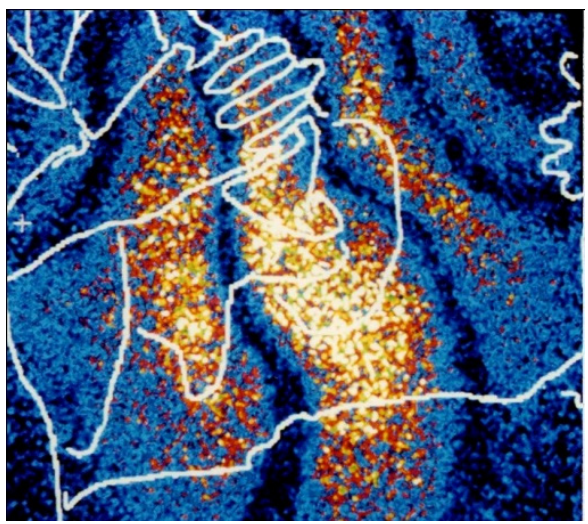

Figure 9: The same area as in Figure 5 after restoration. Specklegram filtering, enhancement and in false colour with the indication of the final design. (See online for colour version.) 
The choice of using the thermographic technique instead of the ESPI technique after the earthquake, is due both for a security issue and to capture by a single frame a larger area. In fact, IR thermography is a telemetric monitoring technique and for working with the ESPI it would have been necessary to mount a scaffold with a significant increase in the inspection costs.

The inspected region with IR thermography corresponds to the area delineated by the large (yellow) rectangle in Figure 10(a).

Figure $10(\mathrm{~b})$ is a phasegram obtained by pulsed phase thermography on the whole data sequence, i.e. including heating and cooling phases. It is possible to see here different kinds of cracks, the same detected before the restoration, and also some surface features, such as painting traces (note the hand at the centre).

Principal component thermography was applied to the heating and cooling phases separately. Results are shown in Figure 10(c) and (d), respectively. During the heating phase, which lasts for $180 \mathrm{~s}$, the thermal signature of surface and near to the surface features is very high. Hence, features in Figure 10(c) are located at the surface or close to it, for instance, the lady's hand and cloths painting traces near the centre of the image. In the case of the cooling phase,

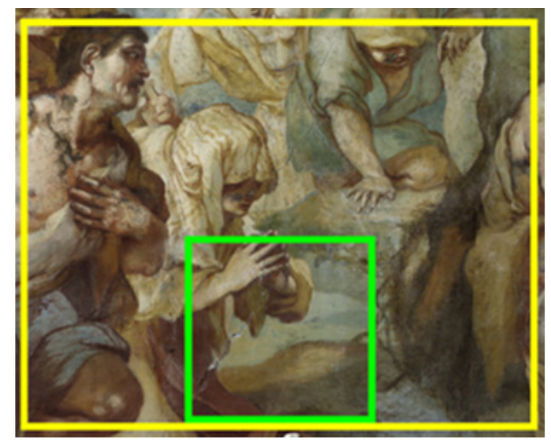

(a)

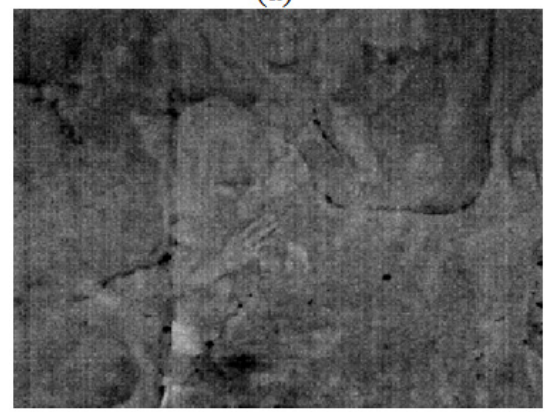

(c)

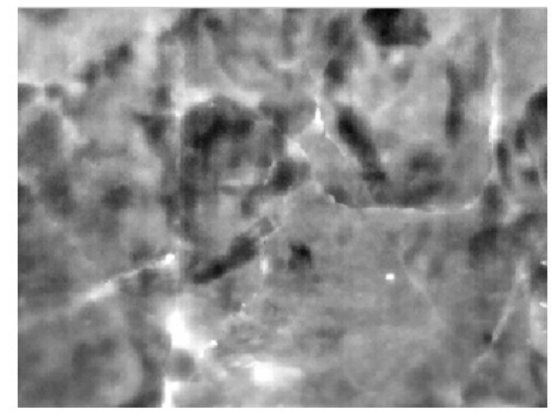

(b)

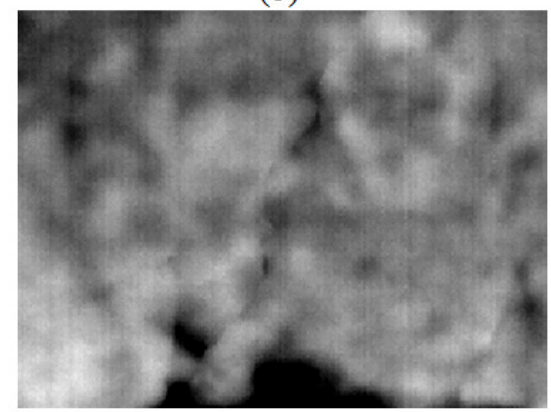

(d)

Figure 10: Active thermography results: (a) Photograph of the inspected area; (b) phasegram obtained by pulsed phase thermography; and principal component thermography results for (c) the heating phase and (d) the cooling phase of the sequence. 
deeper features are seen since heat has the time to propagate through the material.

In order to detect underdrawings and show more clearly the surface defects that occurred after the earthquake, the NIR (Near-Infrared Reflectography) technique was also used on the same area analyzed by IR thermography (Figure 11). It was shown that most pigments are transparent in $0.7-2.5 \mu \mathrm{m}$ band and, thus, underdrawings can be viewed by using a NIR camera such as vidicon, or CCD-based cameras introduced in 1990s (Obrutsky and Acosta [27]).

As can be seen from Figure 11, there were no underdrawings, but this technique enhances the surface and subsurface cracks, as we compare this result with the photo of the same area shown in Figure 10(a). The emissivity of a pigment, highlighted with a black rectangle (Figure 11), is enhanced by NIR technique. This pigment was analyzed in a laboratory and identified as white lead (Figure 12).

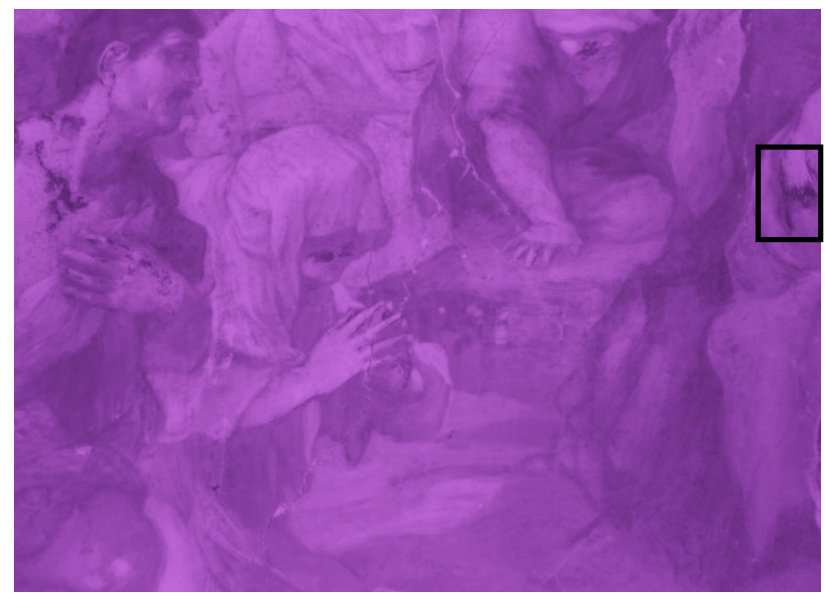

Figure 11: NIR result on the same area analyzed by IR Thermography reported as (yellow) rectangle in Figure 10(a). (See online for colour version.)

In fact, white lead has a measurable radioactive trace with appropriate tools, which can roughly determine the age and disappears completely after a minimum period of 160 years. Drying is fast enough and produces a very elastic film, robustness cannot be reached with any other white, but tends to lose coverage, over the years. It tends to darken, due to the action of hydrogen sulphide traces in the air; in fact, oxidized, it turns into lead oxide, brown in colour. This tendency to become dark is much more evident when it is used with binders (mural painting, tempera) and in the presence of moisture (Piva [28]). Note how the relative humidity measured during the thermographic acquisition was $58.9 \%$. 


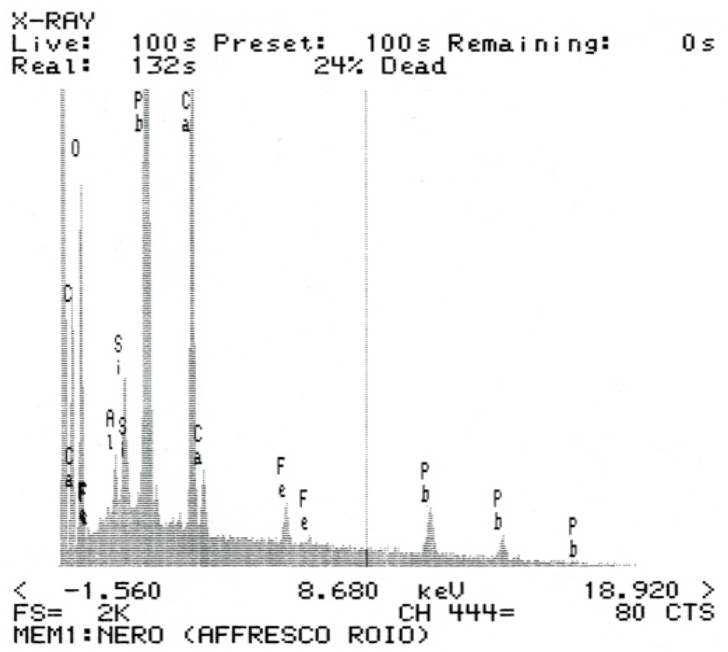

Figure 12: X-ray diffractometer of the particular pigment highlighted with a black rectangle in Figure 11.

\section{Conclusion}

Many current methods of optical testing are not widely available for the examination of frescoes because laboratory facilities are required. The satisfactory operation of the TV holographic system described in this work is illustrated by its application to the analysis of Farelli's fresco situated inside Santa Maria della Croce di Roio Church: the system is very simple to use in situ. The same consideration is possible for square pulsed thermography used outside the laboratory. This work confirms that ESPI and thermographic techniques may be considered generally for all types of work where one can foresee a degrading reaction to ambient stimuli or mechanical stress (e.g. earthquake); these stimuli generally cause internal detachments and cracks due to structural instabilities. Another consideration is the importance of monitoring program following the restoration of a fresco of great historical value. In fact, the same cracks that led to the restoration in 2004 (Figure 7) were reassessed following the earthquake of 2009 (Figure 10b), at least for the area highlighted with a green rectangle (Figure 5 ), where there was overlapping of optical, NIR and thermographic techniques. This integrated result can be easily interpreted by the restorer who will focus on restoration of this work of art.

\section{Acknowledgements}

The authors want to thank the support of the Soprintendenza per $i$ Beni Ambientali, Architettonici, Artistici e Storici per l'Abruzzo (Italy) for granting permission to carry out experiments on the Farelli's frescoes in the Santa Maria 
640 Structural Repairs and Maintenance of Heritage Architecture XII

della Croce di Roio Church and for providing us the result of X-ray diffractometer.

\section{References}

[1] Arendt, C., The Role of the Architectural Fabric in the Preservation of Wall Painting, Proceedings of a symposium organized by the Courtauld Institute of Art and the Getty Conservation Institute, London, July 13-16, Sharon Cather, Ed, 1987.

[2] Antonucci, E., Roio e il suo Santuario, Editrice Eco, S. Gabriele dell'Addolorata (TE), 1986.

[3] Murri, F., Roio e la sua storia, Editrice La Fonte, Pescara, 1989.

[4] Paoletti, D. and Schirripa Spagnolo, G., The potential of portable TV holography for examining frescoes in situ, Studies in Conservation, 40, 1995.

[5] Merrifield, M.P., The art of fresco painting in the middle ages and the renaissance, U.S.A., Dover Publications, Inc., 2004.

[6] Goodman, J.W., in: Laser speckle and related phenomena, Topics in Applied Physics, Vol. 9, ed. J.C. Dainty (Springer, Berlin), p.9, 1975.

[7] Butters, J.N. and Leedertz, J.A., J. Meas. Cont. 4, 349, 1971.

[8] Macovski, A., Ramsey, S.D. and Schaefer, L.F., Appl. Opt. 10, 2722, 1971.

[9] Schwomma, O., Osterreichisches Patent 298 830, 1972.

[10] Ennos, A.E., in: Laser speckle and related phenomena, Topics in Applied Physics, Vol. 9 ed. J.C. Dainty (Springer, Berlin), p. 203, 1975.

[11] Lokberg, O.J. and Malmo, J.T., Long-distance electronic speckle pattern interferometry, Opt. Eng. 27, 150-156, 1988.

[12] Paoletti, D. and Schirripa Spagnolo, G., Application of fibre optic digital speckle interferometry to mural painting diagnostics, Meas. Sci. Technol. 4: 614-618, 1993.

[13] Kato, J., Yamaguchi, I. and Ping, Q., Automatic deformation analysis by a TV speckle interferometer using a laser diode, Appl. Opt., 32: 77-83, 1993.

[14] Zanetta, P., Optical techniques applied to measurement in Art, Ph.D. Thesis, Loughborough University of Technology (UK) Technical note ISEI/IE/2777/94, Commission of the European Communities, Joint Research Center, ISPRA Site, 1994.

[15] Albrecht, D., Electronic speckle pattern interferometry instruments development, Optimization and Applications, Ph.D. Thesis, Loughborough University of Technology (UK) Special Publication No. I.99.40, Commission of the European Communities, Joint Research Center, ISPRA Site, 1999.

[16] Thomson, W.T., Theory of Vibration with Application, New York: Prentice-Hall, 20-200, 1972.

[17] Maldague, X.P.V., Theory and practice of infrared technology for nondestructive testing, (John Wiley \& Sons, New York), p. 251, 2001.

[18] Balageas, D.L., Krapez, J.C. and Cielo, P., Pulsed Photothermal Modeling of Layered Materials, J. of Appl. Phys. 59(2):348-357, 1986. 
[19] Vavilov, V., Kauppinen, T. and Grinzato, E., Thermal characterization of defects in building envelopes using longsquare pulse and slow thermal wave techniques, Research in Nondestructive Evaluation, 9:181-200, 1997.

[20] Arndt, R.W., Square pulse thermography in frequency domain as adaptation of pulsed phase thermography for qualitative and quantitative applications in cultural heritage and civil engineering, Infrared Physics \& Technology, 53:246-253, 2010.

[21] Rajic, N., Principal component thermography for flaw contrast enhancement and flaw depth characterization in composite structures, Compos. Struct., 58:521-528, 2002.

[22] Marinetti, S., Grinzato, E., Bison, P.G., Bozzi, E., Chimenti, M., Pieri, G. and Salvetti, O., Statistical analysis of IR thermographic sequences by PCA, Infrared Phys. \& Technol., 46:85-91, 2004.

[23] Maldague, X.P. and Marinetti, S., Pulse Phase Infrared Thermography, J. Appl. Phys., 79(5):2694-2698, 1996.

[24] Ibarra-Castanedo, C. and Maldague, X., Pulsed Phase Thermography Reviewed, QIRT J., 1(1):47-70, 2004.

[25] Meola, C. and Carlomagno, G.M., Recent Advances in the Use of Infrared Thermography, Meas. Sci. Technol., 15:27-58, 2004.

[26] Kreis, T., Digital holographic interference-phase measurement using the Fourier-transform method, J. Opt. Soc. Am., 6:847-855, 1986.

[27] Obrutsky, A. and Acosta, D., Reflectography, a NDT method for images diagnosis, Proceedings of $16^{\text {th }}$ World Conference on NDT, pp. 46-51, 2004.

[28] Piva, G., L'arte del restauro - Il restauro dei dipinti nel sistema antico e moderno - Third Edition, Hoepli Ed., Milano, 1988. 